\title{
Immunoassay for Detection of Feline Immunodeficiency Virus Core Antigen
}

\author{
GARRETT K. TILTON, ${ }^{1}$ THOMAS P. O'CONNOR, JR., ${ }^{1 *}$ CYNTHIA L. SEYMOUR, ${ }^{1}$ KAREN L. LAWRENCE, ${ }^{1}$ \\ NOAH D. COHEN, ${ }^{2}$ PHILIP R. ANDERSEN, ${ }^{1}$ AND QUENTIN J. TONELLI ${ }^{1}$ \\ IDEXX Corporation, Portland, Maine 04101, ${ }^{1}$ and Department of Large Animal Medicine and Surgery, College of \\ Veterinary Medicine, Texas A\&M University, College Station, Texas $77843^{2}$
}

Received 21 September 1989/Accepted 23 January 1990

\begin{abstract}
The feline immunodeficiency virus (FIV) is a recently identified feline lentivirus that has been found at significant levels in domestic cat populations worldwide. A microdilution plate format, monoclonal antibodybased enzyme-linked immunosorbent assay was developed for the detection of the FIV group-associated antigen (gag) designated p24. Assays of serially diluted samples containing disrupted virus showed that the assay had a sensitivity limit of approximately $0.2 \mathrm{ng} / \mathrm{ml}$ for FIV p24. The assay was approximately eightfold more sensitive than the assay for viral reverse transcriptase activity when it was tested with diluted tissue culture samples. A qualitative confirmation assay by standard antibody inhibition techniques was coupled to the screening test methodology. The test was used to detect and confirm the presence of virus in cultured feline lymphocytes from infected animals.
\end{abstract}

The feline immunodeficiency virus (FIV), formerly feline T-lymphotropic lentivirus, is a feline retrovirus that can produce chronic immunodeficiency-like disorders in cats $(21,22)$. The FIV agent has a strong, but not absolute, tropism for the feline T-lymphocyte cell line, which may be responsible for the immunosuppressive nature of the virus. The virus has been classified as a lentivirus based on the morphology of the viral particle and the $\mathrm{Mg}^{2+}$ requirement of the viral reverse transcriptase $(9,24,29)$. The virus represents the initial description of a feline lentivirus (22). Members of the lentivirus subfamily that infect other species include the human immunodeficiency viruses $(5,15)$, simian immunodeficiency virus (1), visna virus (18), caprine arthritis-encephalitis virus (4), equine infectious anemia virus (20), and bovine immunodeficiency-like virus (6).

FIV is infectious within domestic cat populations and has been transmitted following prolonged contact (22). FIV infection has been reported in the United States, Canada, Europe, and Japan $(8,10,28)$. Results of a serosurvey in the United States $(n=1,556)$ demonstrate that infection is fairly common in both clinic (5.2\%) and sick (15.2\%) cat populations (19). Several additional seroepidemiological surveys have found similar infection rates $(7,10,23,27,28)$.

A 24,000-dalton protein (p24) has been identified as an FIV group-associated antigen and is the predominant core structural protein of the virus (R. Steinman, J. Dombrowski, T. O'Connor, R. C. Montelaro, Q. Tonelli, K. Lawrence, C. Seymour, J. Goodness, N. Pedersen and P. R. Andersen, J. Gen. Virol., in press). The major core protein of FIV was initially designated as p26; the nomenclature was derived from the estimation of its molecular mass based on migration in polyacrylamide gels. However, recent genetic sequence data show that the molecular mass is approximately 24,000 daltons and indicate that the protein should be designated p24 (25). In this report, we describe a microdilution platebased enzyme-linked immunosorbent assay (ELISA) for the detection of FIV p24 antigen. The FIV-antigen ELISA is a qualitative and quantitative test that can be used to detect and monitor the growth of virus in tissue culture samples.

\footnotetext{
* Corresponding author.
}

The assay can be used to confirm the presence of virus in tissue culture fluids following culturing of lymphocytes from feline blood or tissue extracts.

\section{MATERIALS AND METHODS}

Virus and cell culture. FIV (Petaluma strain) was propagated in chronically infected Crandell feline kidney (CRFK) cells (3). The virus is noncytopathogenic for CRFK cells and was concentrated from tissue culture fluids by precipitation with polyethylene glycol (2) and purified by density gradient centrifugation on glycerol gradients as described previously (16). Purified feline leukemia virus was obtained from Electronucleonics (Fairfield, N.J.). Feline infectious peritonitis virus (strain 79-1146) was obtained from the American Type Culture Collection (Rockville, Md.).

Monoclonal antibody production. BALB/cJ mice (Jackson Laboratory, Bar Harbor, Maine) were immunized with disrupted FIV mixed with an equal volume of complete adjuvant H37Ra (Difco Laboratories, Detroit, Mich.). Mice were boosted 2 weeks later with the same antigen preparation in incomplete adjuvant. Fusions with $\mathrm{P} 3 \times 63-\mathrm{Ag} 8.653$ mouse myeloma cells and immunized mouse spleen cells were performed 3 days after the last injection $(11,12)$. Hybridomas were grown in hypoxanthine-aminopterin-thymidine medium and screened by using FIV-coated microdilution plates (IDEXX Corp, Portland, Maine). The FIV antigencoated microdilution plates were prepared as described previously (19).

Anti-FIV monoclonal antibody ELISA. The anti-FIV monoclonal antibodies were purified by ammonium sulfate precipitation followed by protein-A Sepharose chromatography (Pharmacia, Inc., Piscataway, N.J.). Microdilution wells were coated overnight with $200 \mu \mathrm{l}$ of purified 2D4 immunoglobulin $\mathrm{G}(\mathrm{IgG} ; 7.5 \mu \mathrm{g} / \mathrm{ml})$ at 3 to $5^{\circ} \mathrm{C}$. Wells were washed with phosphate-buffered saline- $0.05 \%$ Tween 20 , blocked with $1 \%$ bovine serum albumin in Tris buffer, and dried. The purified 4F2 monoclonal antibody was conjugated to horseradish peroxidase (HRPO; Boehringer Mannheim Biochemicals, Indianapolis, Ind.) by the procedure initially described by Nakane and Kawaoi (17).

Screening assay. Twenty microliters of lysis buffer contain- 
ing $5.0 \%$ Triton $\mathrm{X}-100$ was added to microdilution wells followed by the addition of $200 \mu$ l of test sample. Plates were incubated for $2 \mathrm{~h}$ at room temperature, aspirated, and washed (five times). Two hundred microliters of anti-FIVHRPO conjugate was added to microdilution wells, incubated for $30 \mathrm{~min}$ (room temperature), aspirated, and washed (five times). Two hundred microliters of substrate-chromogen solution $(0.05 \%$ tetramethylbenzidine, $0.02 \%$ hydrogen peroxide, phosphate-citrate buffer [ $\mathrm{pH} 4.8]$ ) was added to microdilution wells and incubated for $30 \mathrm{~min}$ (room temperature), and the reaction was terminated with $50 \mu l$ of dilute hydrofluoric acid (1:200). Individual microdilution well $A_{650}$ values were determined spectrophotometrically.

Positive control (PC) and negative control (NC) reagents were assayed on each microdilution plate to validate individual assays and calculate the assay cutoff. The NC contained $10 \%$ bovine serum albumin; the PC contained a standardized level of disrupted FIV in $10 \%$ bovine serum albumin. The screening assay cutoff was calculated by adding 0.150 absorbance units to the mean $A_{650}$ value of duplicate NC assays. The difference between the $A_{650}$ value of the PC and the mean $A_{650}$ value of the NC assays was greater than 0.500 units, and the mean $A_{650}$ of the NC was less than 0.250 units for all valid assays. An experimental NC sample consisting of the medium that was used to dilute FIV was assayed and compared with the NC to determine reagent compatibility. The $A_{650}$ of the experimental negative control sample was \pm 0.1 absorbance units of the $\mathrm{NC}$ mean $A_{650}$ for all assays.

Confirmatory assay. The confirmatory assay incorporated a sample preincubation step with feline polyclonal anti-FIV antibody (blocking reagent). The rest of the assay was performed as described above for the screening assay. Reactive samples and the PC were each divided into two $200-\mu l$ portions and were treated individually with either 40 $\mu$ l of sample diluent (aliquot A) or $40 \mu$ l of pooled anti-FIV antibody positive sera (aliquot B). These were incubated for $15 \mathrm{~min}$, and $200-\mu \mathrm{l}$ samples were added to microdilution wells and assayed as described above. The confirmatory test cutoff was calculated by adding 0.125 absorbance units to the NC $A_{650}$ value. In valid confirmatory assays, the $A_{650}$ of the PC minus the $A_{650}$ of the NC was greater than or equal to 0.500 units and the $A_{650}$ of the NC was less than 0.250 units. In addition, the $A_{650}$ value of the PC was reduced by greater than $50 \%$. A sample was confirmed positive if the $A_{650}$ value of the aliquot $A$ sample was greater than the confirmatory test cutoff and if the $A_{650}$ value of the aliquot B sample was reduced by $50 \%$ or more relative to the $A_{650}$ value of the aliquot A sample. It was necessary for the $A_{650}$ value of the aliquot A sample to be less than 2.0. Samples with $A_{650}$ values of greater than 2.0 were diluted $1: 10$ and retested.

Additional assays and reagents. The protein concentration of purified FIV samples was determined by the bicinchoninic acid protein assay (Pierce Chemical Co., Rockford, Ill.) by using bovine serum albumin as a standard. Polyacrylamide gel electrophoresis in the presence of sodium dodecyl sulfate was performed as described by Laemmli (13) by using $10 \%$ polyacrylamide gels. Proteins were visualized by staining the gels with Coomassie brilliant blue R-250 (Sigma Chemical Co., St. Louis, Mo.) and amido black 10B (Bio-Rad Laboratories, Richmond, Calif.). The relative content of p24 in the purified FIV preparations was estimated by densitometric scanning of the Coomassie brilliant blue- and amido black-stained polyacrylamide gels by using a scanning densitometer (GS-300; Hoefer Scientific, San Francisco, Calif.) and software package (Hoefer Scientific). The calculated p24 content of the FIV preparation was essentially equivalent following Coomassie brilliant blue and amido black staining and was not stain dependent. The p24-antigen serial dilution panel was prepared in $20 \%$ bovine serum albumin following disruption of FIV by heating $\left(65^{\circ} \mathrm{C}, 1 \mathrm{~h}\right) \mathrm{FIV}$ in the presence of $0.5 \%$ sodium dodecyl sulfate.

The Western blot (immunoblot) protocol used in this study was a modification of the procedure initially reported by Towbin et al. (26) and has been described previously (19). Goat anti-mouse HRPO conjugate (Accurate Chemical Co., Westbury, N.Y.) was used for assays of mouse monoclonal antibodies.

Isolation and culturing of FIV. Peripheral blood lymphocytes (PBLs) were isolated by the Ficoll-Hypaque method from 3 to $5 \mathrm{ml}$ of heparinized feline blood. The PBLs were suspended in culture medium at a final concentration of 0.5 $\times 10^{6}$ to $1.0 \times 10^{6}$ cells per $\mathrm{ml}$ and placed in $25-\mathrm{cm}^{2}$ culture flasks. To this cell suspension, mitogen-stimulated normal donor PBLs were added at normal donor to infected donor PBL ratios of $1: 1$ or $1: 2$. The culture medium consisted of RPMI 1640 with $10 \%$ heat-inactivated fetal bovine serum, 10 mM HEPES ( $N$-2-hydroxyethylpiperazine- $N$ '-2-ethanesulfonic acid), $100 \mathrm{U}$ of penicillin per $\mathrm{ml}, 10 \mu \mathrm{g}$ of streptomycin per $\mathrm{ml}, 2 \mathrm{mM}$ L-glutamine, $2 \mu \mathrm{g}$ of polybrene per $\mathrm{ml}$, and $100 \mathrm{U}$ of human interleukin-2 per ml. Cultures were incubated in $5 \% \mathrm{CO}_{2}$ at $37^{\circ} \mathrm{C}$ and monitored for syncytia formation and other cytopathic effects. Culture supernatants were harvested for reverse transcriptase (RT) activity assays, and cells were suspended in fresh culture medium twice a week. These cultures were further supplemented with mitogen-stimulated normal PBLs from the same donor to maintain a minimum cell concentration of $0.5 \times 10^{6}$ to 1.0 $\times 10^{6}$ cells per ml. Virus production was monitored by syncytia formation and by an RT assay by using $\mathrm{Mg}^{2+}$ as the divalent cation, poly(rA)-oligo $\left(\mathrm{dT}_{12-18}\right)$ as the template primer, and a minimum of $5 \mu \mathrm{Ci}$ of $\left[{ }^{3} \mathrm{H}\right.$ ]TTP per sample (22).

Solid tissue specimens were teased or minced aseptically with forceps and scalpels and suspended in culture medium. The procedure described for PBL samples was then followed for the isolation of lymphocytes and the culturing of FIV.

Preparation of stimulated PBLs from normal cat donors. Specific-pathogen-free (SPF) kittens and cats (Liberty Laboratories, Liberty Corner, N.J.) were used as normal donors of PBLs. Donor PBLs were prepared from heparinized blood ( 5 to $40 \mathrm{ml}$ ) by the Ficoll-Hypaque method. The cells were suspended in culture medium (not supplemented with polybrene or human interleukin-2) and cultured in the presence of $5 \mu \mathrm{g}$ of concanavalin A (ConA; Sigma) per $\mathrm{ml}$ in $5 \%$ $\mathrm{CO}_{2}$ at $37^{\circ} \mathrm{C}$ for 3 days. The stimulated donor PBLs were then harvested, washed with sterile $1 \times$ Hanks balanced salt solution, and either suspended in complete culture medium ready to be used for FIV isolation or suspended in culture medium free of polybrene and recultured for later use.

\section{RESULTS}

Characterization of anti-FIV monoclonal and polyclonal antibodies. The relative binding affinities of the FIV-reactive monoclonal antibodies were compared by using FIV antigencoated microdilution wells and HRPO-conjugated goat antimouse IgG. High-affinity antibodies were purified and used to prepare antibody-coated microdilution wells and HRPO conjugates. Matrix experiments were carried out by using dilutions of inactivated FIV antigen to determine the optimal assay configuration. Assay results for a single concentration of FIV $(10 \mathrm{ng} / \mathrm{ml})$ obtained for six of the anti-FIV monoclo- 
TABLE 1. Optimization of assay configuration: ELISA results as $A_{650}$ values for anti-FIV monoclonal antibodies used as conjugates and to coat microassay wells ${ }^{a}$

\begin{tabular}{lcccccc}
\hline $\begin{array}{c}\text { Monoclonal } \\
\text { antibody- } \\
\text { coated } \\
\text { strip }^{b}\end{array}$ & $6 \mathrm{E} 6$ & $5 \mathrm{E} 2$ & $2 \mathrm{D} 4$ & $3 \mathrm{H} 8$ & $4 \mathrm{~F} 2$ & $4 \mathrm{E} 10$ \\
\cline { 2 - 7 } & & \multicolumn{5}{c}{$\begin{array}{c}\text { value for the following monoclonal } \\
\text { antibody-HRPO conjugates }\end{array}$} \\
\hline 6E6 & 0.135 & 0.417 & 0.096 & 0.125 & 0.385 & 0.338 \\
5E2 & 0.996 & 0.140 & 0.373 & 0.072 & 0.118 & 0.136 \\
2D4 & 1.021 & 0.817 & 0.061 & 0.830 & 1.994 & 1.532 \\
3H8 & 0.831 & 0.121 & 0.250 & 0.069 & 0.111 & 0.101 \\
4F2 & 0.981 & 0.223 & 0.305 & 0.072 & 0.159 & 0.121 \\
4E10 & 0.759 & 0.216 & 0.313 & 0.068 & 0.156 & 0.103 \\
\hline
\end{tabular}

${ }^{a}$ Assays were carried out at a single concentration of FIV antigen (10 ng/ $\mathrm{ml}$ ).

${ }^{b}$ Microdilution wells were coated with $100 \mu$ l of each monoclonal antibody at a concentration of $10 \mu \mathrm{g} / \mathrm{ml}$.

${ }^{c}$ The concentration of each conjugate was $10 \mu \mathrm{g} / \mathrm{ml}$.

nal antibodies are shown in Table 1. Maximal test sensitivity was achieved by using the 2D4 monoclonal antibody to coat the microdilution wells and the 4F2 monoclonal antibody for conjugate preparation.

The FIV subcomponent specificities of the 2D4 and 4F2 monoclonal antibodies were determined by preparing HRPO conjugates and reacting each one with FIV Western blot strips (Fig. 1). Strip A shows the assay result for an FIV antibody-positive serum pool and delineates the positions of FIV-reactive subcomponents (19). Assay results for the 2D4-HRPO and 4F2-HRPO conjugates (lanes D and E, respectively, in Fig. 1) demonstrated that each is specific for the p24 component of FIV. An ELISA was carried out to

\section{A. B. C

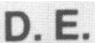

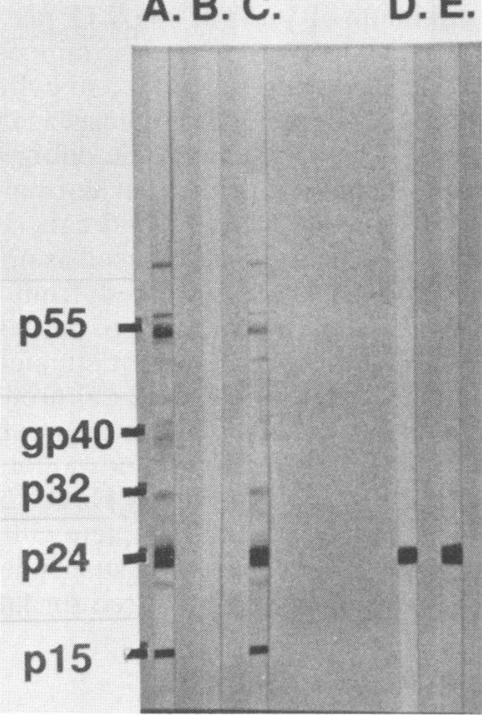

FIG. 1. Western blot (immunoblot) assays of the anti-FIV-positive serum pool (lane A), negative control (lane B), FIV-blocking reagent (lane C), and the anti-FIV-HRPO conjugates 2D4-HRPO (lane D) and 4F2-HRPO (lane E). Feline samples were diluted $(1: 100)$ in sodium phosphate buffer ( $\mathrm{pH} 7.4)$ containing $30 \%$ calf serum and incubated for $1 \mathrm{~h}$ with the lanes containing FIV. These were washed, incubated with anti-feline-HRPO, washed again, and reacted with $\mathrm{H}_{2} \mathrm{O}_{2}$ and 4-chloronaphthol. The anti-FIV-HRPO monoclonal antibody conjugates were assayed in a similar fashion with elimination of the anti-feline-HRPO conjugated reaction. gp40, Glycoprotein 40 .
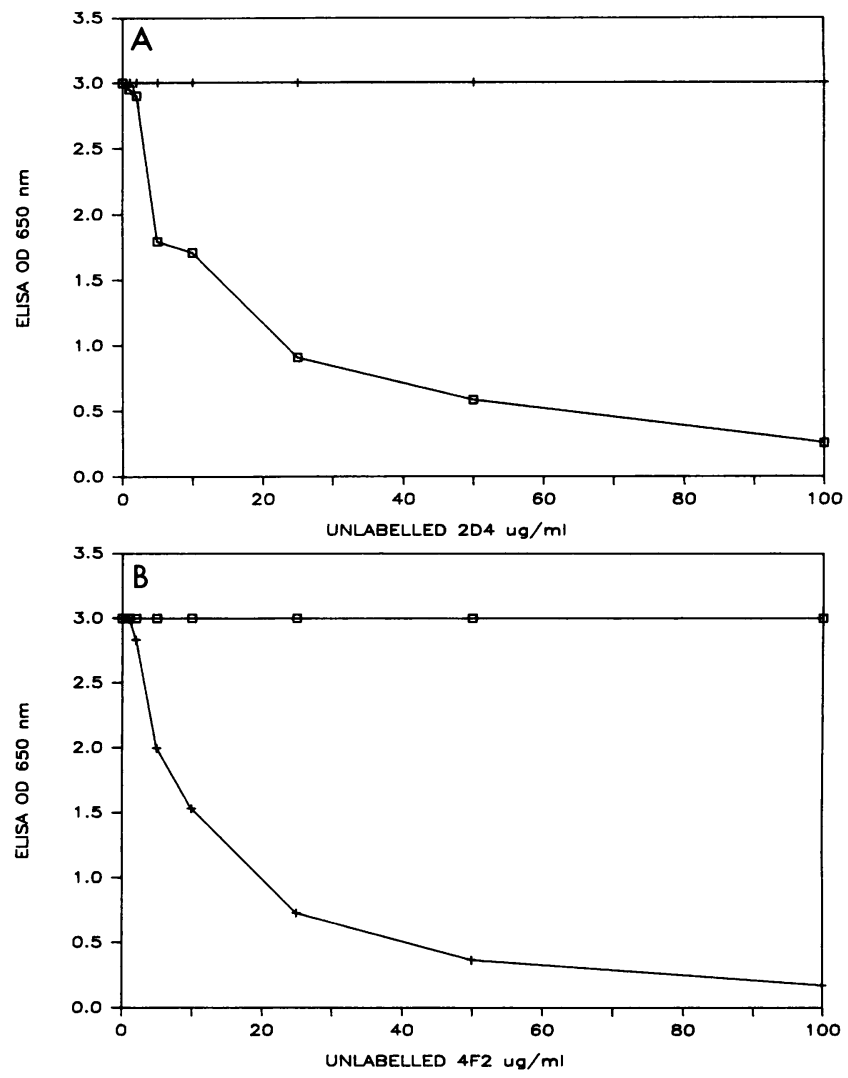

FIG. 2. Monoclonal antibody epitope analysis. The relative binding of a constant concentration $(10 \mu \mathrm{g} / \mathrm{ml})$ of 2D4-HRPO ( $\square$ ) and 4F2-HRPO (+) to an FIV antigen-coated microdilution well was measured in the presence of various levels $(0$ to $100 \mu \mathrm{g} / \mathrm{ml})$ of unconjugated 2D4 (A) and 4F2 (B). OD, Optical density.

determine whether the 2D4 and 4F2 monoclonal antibodies compete for binding to a single p24 epitope. The relative binding of each HRPO conjugate to FIV-coated microdilution wells was measured in the presence of various levels of unconjugated 2D4 and 4F2 (Fig. 2). The lack of competition

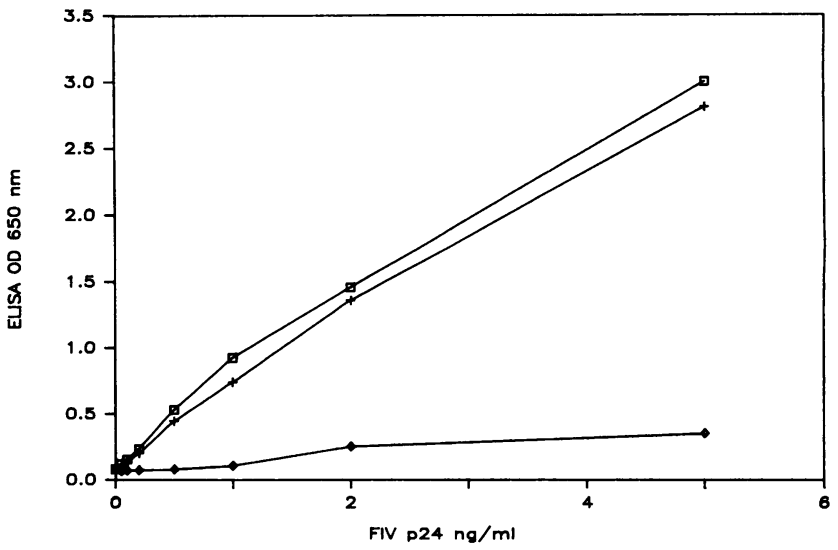

FIG. 3. FIV-antigen ELISA optical density (OD) values for disrupted virus samples containing less than 5.0 ng of FIV p24 per $\mathrm{ml}$. Screening and confirmatory assays were conducted as described in the text and had assay cutoff values of 0.221 and 0.196 , respectively. Symbols: $\square$, screening; +, aliquot A; $\diamond$, aliquot B. 
$1: 10^{1}$

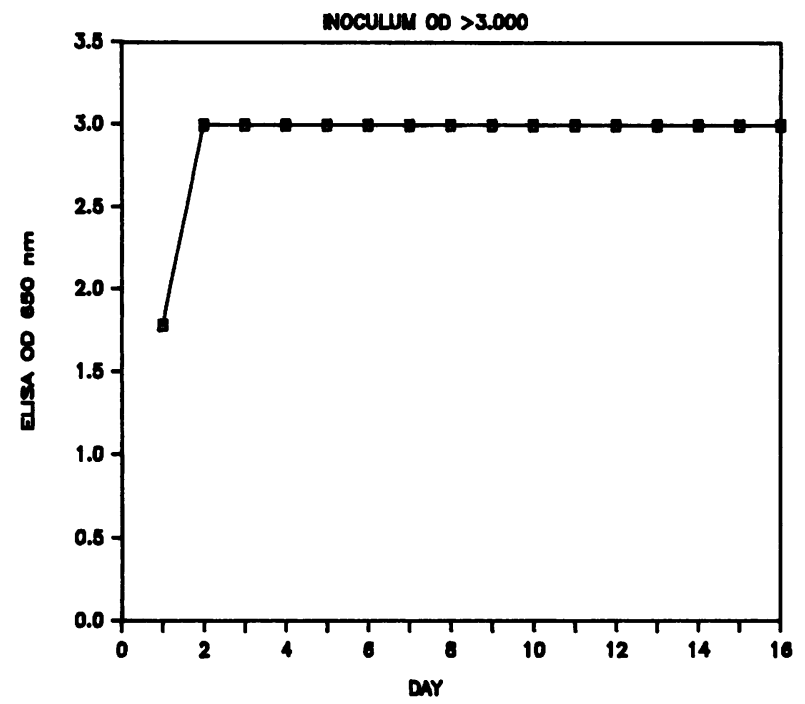

$1: 10^{5}$

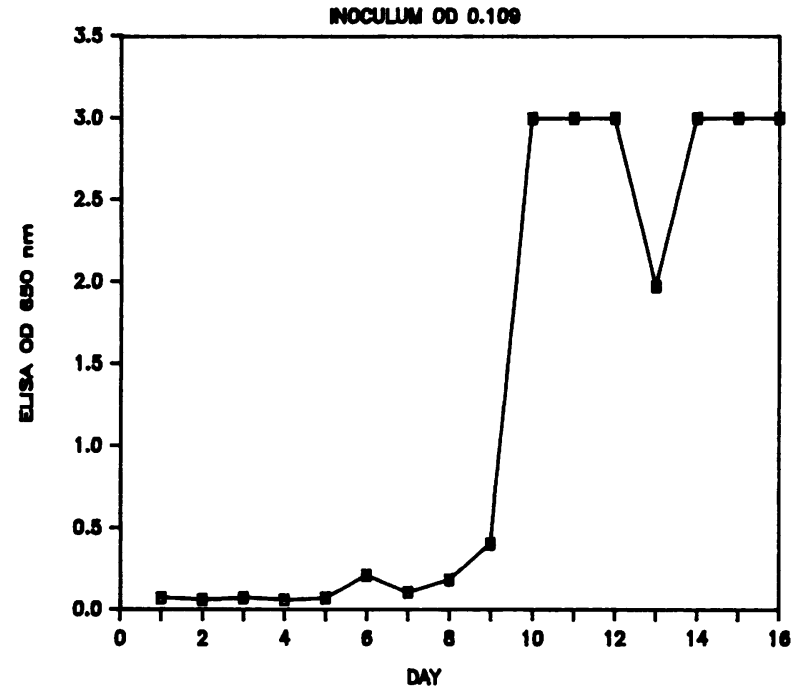

$1: 10^{3}$

moculun oD $>3.000$

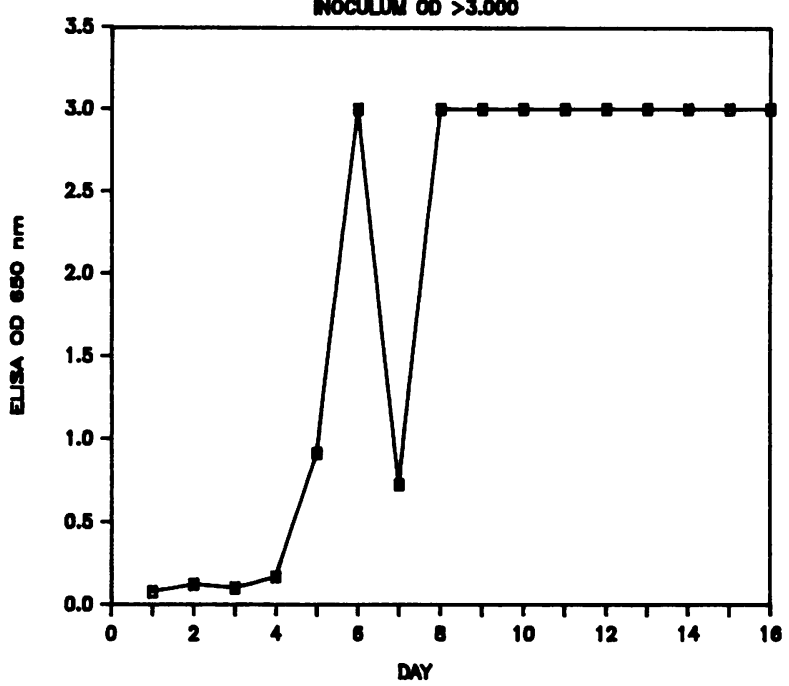

$1: 10^{6}$

Moculum 000.077

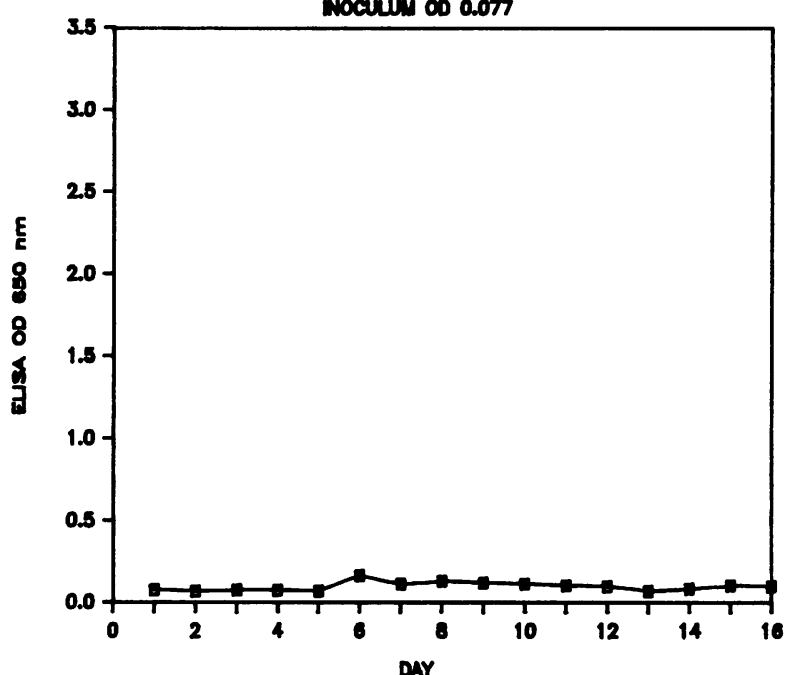

FIG. 4. The FIV endpoint titration experiment was conducted with 10-fold serial dilutions of an FIV-containing tissue culture fluid prepared in uninfected tissue culture medium. The inoculum $A_{650}$ is the FIV-antigen ELISA result for each serial dilution prior to the initiation of the cell culture. Experimental conditions are described in the text. OD, Optical density.

between 2D4-HRPO and 4F2 and between 4F2-HRPO and 2D4 indicates that the monoclonal antibodies react with different epitopes of FIV.

The blocking reagent used in the confirmatory procedure was a high-titer pool of feline anti-FIV positive sera. The pooled reagent showed a strong reaction to the FIV-specific proteins p15, p24, p32, gp40, p47, and p65 when tested by the Western blot assay (Fig. 1, lane C). The blocking reagent inhibited binding of both 2D4-HRPO and 4F2-HRPO to FIV-coated microdilution wells when tested in a competition ELISA (data not shown).

The monoclonal antibodies used in the FIV-antigen ELISA showed no reaction when they were tested with concentrated samples of feline leukemia virus or feline infectious peritonitis virus. A dilution series of each virus was prepared in fetal bovine serum and tested by virusspecific assays and by the FIV-antigen ELISA. Dilutions of feline leukemia virus $(1: 1,000$ to $1: 32,000)$ were positive by the PetChek feline leukemia virus-antigen ELISA (IDEXX Corp.), and dilutions of feline infectious peritonitis virus $(1: 10$ to $1: 10,000)$ were positive in a tissue culture assay for feline infectious peritonitis virus. Each of these samples was negative when tested by the FIV-antigen ELISA (data not shown).

Assay sensitivity. A p24 serial dilution panel (0.05 to 1,000 $\mathrm{ng} / \mathrm{ml}$ ) was prepared in $20 \%$ bovine serum albumin as described in Materials and Methods. The panel was tested by the FIV-antigen ELISA by using both the screening and confirmatory procedures. Results for samples containing less than $5 \mathrm{ng}$ of $\mathrm{p} 24$ per $\mathrm{ml}$ are represented in Fig. 3. Samples containing greater than $5 \mathrm{ng} / \mathrm{ml}$ gave screening assay $A_{650}$ values of greater than 3.0 (data not shown). The confirmatory diluent control $A_{650}$ value (aliquot A) was slightly less than the corresponding $A_{650}$ value obtained in the screening test and reflects the 1.2 -fold sample dilution that occurred following the addition of the confirmatory 

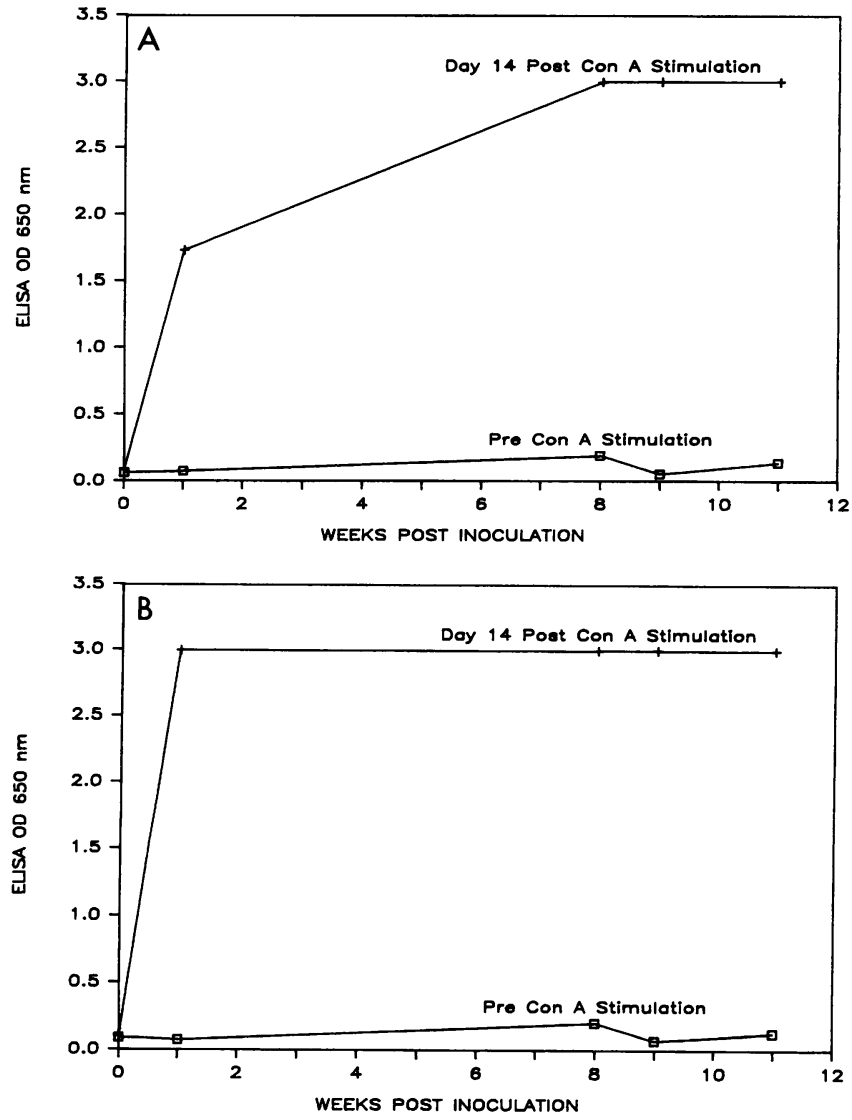

FIG. 5. The experimental infection temporal series was conducted by inoculation of two SPF cats (HV1 [A] and IB2 [B]) with blood from a confirmed FIV antibody-positive animal (Ch). Lymphocytes were obtained several times postinoculation and were added to tissue culture medium. Tissue culture fluids were sampled before and 14 days following stimulation of lymphocytes with conA. Symbols: $\square$, prestimulation; +, poststimulation.

reagent (Fig. 3). Both assays had a sensitivity limit of approximately $0.2 \mathrm{ng}$ of p24 per ml. Specific viral inhibition (inhibition values of greater than $50 \%$ ) was confirmed for each panel member.

In a separate study, the sensitivity of the antigen-capture ELISA was compared with that of the assay of viral RT activity. Twofold serial dilutions of FIV were prepared in FIV-negative tissue culture medium by using a tissue culture sample containing untreated FIV. These were tested by the FIV-antigen ELISA and by enzymatic assay of viral RT activity. The assay cutoff for the FIV-antigen ELISA was $0.231(\mathrm{NC}+0.150)$; the last serial dilution that was positive by this assay was $1: 25,600$. The cutoff for the RT activity assay (estimated to be twice the background corrected value of the negative control mean counts per minute) was 1,427 cpm. The last serial dilution that was positive by the RT activity assay was 1:3,200 (data not shown).

A series of experiments was conducted to determine the endpoint dilution of an FIV culture and to estimate the length of time required for detection of FIV antigen in tissue culture. Tenfold serial dilutions of tissue culture fluid containing FIV were prepared in uninfected tissue culture medium. Samples of the dilution series (ranging from 1:10 1 to $1: 10^{6}$ ) were first assayed by the FIV-antigen ELISA and then used to inoculate uninfected CRFK cultures at $50 \%$ confluency. Samples of tissue culture fluid were withdrawn daily
TABLE 2. ELISA detection of FIV antigen in CRFK cells cocultivated with splenic lymphocytes derived from an FIV-positive cat

\begin{tabular}{ccc}
\hline $\begin{array}{c}\text { Incubation time } \\
\text { (days) }\end{array}$ & ELISA $\boldsymbol{A}_{650}{ }^{a}$ & \% Inhibition \\
\hline 0 & 0.158 & \\
7 & 0.602 & 84 \\
15 & 2.641 & 96 \\
20 & 1.529 & 95 \\
\hline
\end{tabular}

${ }^{a}$ Assay cutoff, 0.258 .

and tested for the presence of FIV by the FIV-antigen ELISA.

Assay results for samples in the dilution series are represented by the individual graphs shown in Fig. 4. The FIV-antigen ELISA result for each dilution sample prior to infection of the CRFK culture is given above each graph. The time needed to productively infect each CRFK culture increased with the dilution of FIV. The $1: 10^{5}$ dilution sample was the highest dilution panel member to productively infect the CRFK culture. This required a 9-day incubation period.

Application of antigen-capture ELISA for the detection of FIV infection. (i) SPF cats. Lymphocytes were isolated from whole blood of four SPF cats ( $\mathrm{Sa}, \mathrm{Sh}, \mathrm{Si}$, and $\mathrm{Sl}$ ) and were used to inoculate tissue culture medium as described in the Materials and Methods. Tissue culture samples $(0.2 \mathrm{ml})$ were obtained 14 days after lymphocyte stimulation and were assayed by the FIV-antigen ELISA. Each of the tissue culture supernatants derived from the SPF cats was negative for FIV antigen after 14 days (data not shown).

(ii) FIV antibody-positive cats. Blood samples from five FIV antibody-positive field cats ( $\mathrm{Ot}, \mathrm{Sc}, \mathrm{Ch}, \mathrm{Da}$, and $\mathrm{St}$ ) were obtained. These were positive by the PetChek FIVantibody ELISA (IDEXX Corp.) and were confirmed to be positive by the FIV Western blot assay. Lymphocytes were obtained from these samples, used to inoculate tissue culture medium, and stimulated as described above. The tissue culture fluids were sampled 14 days following inoculation and assayed by the FIV-antigen ELISA. Each of the tissue culture supernatants derived from the FIV antibody-positive cats was positive after 14 days. All were confirmed to be positive by the FIV-specific inhibition assay (data not shown).

(iii) Temporal series. Two SPF cats (HV1 and IB2) were inoculated (intraperitoneally) with whole blood $(2.0 \mathrm{ml})$ from one of the confirmed FIV-positive cats described above (Ch). Samples of whole blood were obtained from the experimentally infected cats (HV1 and IB2) before and at several times after inoculation. Lymphocytes were isolated from these whole blood samples and were added to the tissue culture medium. The tissue culture fluids were sampled before and 14 days following stimulation of lymphocytes with ConA.

The FIV-antigen ELISA results for tissue culture samples are presented in Fig. 5. All tissue culture samples obtained prior to lymphocyte stimulation were negative. Lymphocytes derived from preinoculation blood samples failed to produce detectable virus after 14 days, while all lymphocytes derived from postinoculation blood samples produced high levels of virus after 14 days. All samples testing positive by the screening assay were confirmed to be positive by the confirmatory procedure. To demonstrate that the experimentally infected animals had seroconverted following the initial inoculation, serum samples from cats HV1 and IB2 were tested by the FIV-antibody ELISA (IDEXX Corp.). 
Both animals were positive for antibody to FIV by week 1 (data not shown).

(iv) Tissue sample. The spleen was obtained from a confirmed FIV antibody-positive cat $(\mathrm{Ch})$. The tissue was homogenized and lymphocytes were isolated by density gradient centrifugation, as described in Materials and Methods. These were cocultivated with CRFK cells, stimulated with ConA, and incubated at $37^{\circ} \mathrm{C}$ for 20 days. Tissue culture samples $(0.2 \mathrm{ml})$ were obtained at several times as described above and assayed by the FIV-antigen ELISA. The FIVantigen ELISA results are shown in Table 2. Spleen lymphocytes from the FIV-positive animal produced high levels of virus in tissue culture after 7 days and throughout the entire test period ( 20 days).

\section{DISCUSSION}

Results of the anti-FIV monoclonal antibody characterization experiments demonstrate that the 2D4 and 4F2 monoclonal antibodies are directed against different epitopes of FIV p24 and are suitable for use in a sandwich ELISA. The FIV-blocking reagent contains antibodies directed against epitopes on p24 that are recognized by 2D4 and 4F2 and block the binding of these monoclonal antibodies to p24. To ensure that the potency of the blocking reagent was sufficient to saturate potential monoclonal antibody-binding sites, the maximum $A_{650}$ value for the diluent-treated sample (aliquot A) in the confirmatory assay was limited to 2.0. In a qualified confirmation assay, aliquot $A$ samples that gave optical density values greater than 2.0 were diluted 1:10 and retested.

The results of the FIV-antigen ELISA correlated with measurements of RT enzymatic activity for untreated virus in tissue culture samples. The FIV-antigen ELISA was three twofold serial dilutions more sensitive than the assay for viral RT activity. These results are consistent with similar observations that were made when the sensitivities of the RT assay and p24 antigen-capture ELISAs were compared for the detection of human immunodeficiency virus type 1 in tissue culture samples (14).

The endpoint titration experiment (Fig. 4) was performed to determine the endpoint dilution for an FIV-containing tissue culture sample and to measure the time course of virus production in tissue culture medium. The time required to produce detectable virus in tissue culture varied from 1 to 9 days and was proportional to the dilution of FIV in the initial inoculum. The $1: 10^{5}$ dilution sample was the highest dilution panel member to productively infect the CRFK culture. It is noteworthy that this sample was negative (ELISA optical density, 0.109) when it was tested by the FIV-antigen ELISA prior to inoculation of the CRFK culture. The cell culture step provided the amplification needed to produce a measurable level of virus.

The FIV-antigen ELISA would be useful as a replacement for RT activity assays for monitoring the growth of virus in tissue culture and for monitoring the recovery of virus during virus purification. The assay has application for use by clinicians in the identification of presumptive virus-positive specimens. Samples could be confirmed to be antigen positive by the FIV-antigen ELISA by culturing lymphocytes from feline blood or tissue extracts and monitoring them for the production of virus in tissue culture media.

\section{LITERATURE CITED}

1. Benveniste, R. E., L. O. Arthur, C. C. Tsai, R. Sowder, T. D. Copeland, L. E. Henderson, and S. Oroszlan. 1986. Isolation of a lentivirus from a macaque with lymphoma: comparison with HTLV-III/LAV and other lentiviruses. J. Virol. 60:483-490.

2. Bishop, D. H., L. R. Ruprecht, R. W. Simpson, and S. Spiegelman. 1971. Deoxyribonucleic acid polymerase of Rous sarcoma virus: reaction conditions and analysis of the reaction product nucleic acids. J. Virol. 8:730-741.

3. Crandell, R. A., and E. Q. Despeau. 1959. Cytopathology of feline viral rhinotracheitis virus in tissue cultures of feline renal cells. Proc. Soc. Exp. Biol. Med. 154:1403-1418.

4. Dahlberg, J. E., J. M. Gaskin, and K. J. Perk. 1981. Morphological and immunological comparison of caprine arthritis encephalitis and ovine progressive pneumonia viruses. J. Virol. 39:914-919.

5. Gallo, R. C., S. Z. Salahuddin, M. Popovic, M. Kaplan, B. F. Haynes, R. Redfield, J. Oleske, B. Sofai, G. M. Shearer, J. T. Palker, G. White, P. Foster, and P. D. Markham. 1984. Frequent detection and isolation of cytopathic retroviruses (HTLV-III) from patients with AIDS and at risk for AIDS. Science 224:500-502.

6. Gonda, M. A., M. J. Braun, S. G. Garter, T. A. Kost, J. W. Bess, Jr., L. G. Arthur, and M. J. Van der Maaten. 1987. Characterization and molecular cloning of a bovine lentivirus related to human immunodeficiency virus. Nature (London) 330:388-392.

7. Grindem, C. B., W. T. Corbett, B. E. Ammerman, and M. T. Tomkins. 1989. Seroepidemiological survey of feline immunodeficiency virus infection in cats of Wake County, North Carolina. J. Am. Vet. Med. Assoc. 194:226-228.

8. Harbour, D. A., P. D. Williams, T. J. Gruffydd-Jones, J. Burbridge, and G. R. Pearson. 1988. Isolation of a T-lymphotropic lentivirus from a persistently leucopenic domestic cat. Vet. Rec. 122:84-86.

9. Hardy, W. D. 1988. Feline T-lymphotropic lentivirus: retrovirus-induced immunosuppression in cats. J. Am. Anim. Hosp. Assoc. 24:241-243.

10. Ishida, T., T. Washizu, K. Toriyabe, S. Motoyoshi, I. Tomoda, and N. C. Pedersen. 1989. Feline immunodeficiency virus infection in cats of Japan. J. Am. Vet. Med. Assoc. 194:221-225.

11. Kearney, J. F., A. Radbruch, B. Liesegang, and K. Rajewsky. 1979. A new mouse myeloma cell line which has lost immunoglobulin expression but permits the construction of antibody in secreting hybrid cell lines. J. Immunol. 123:1548-1550.

12. Kohler, G., and C. Milstein. 1975. Continuous cultures of fused cells secreting antibody of predefined specificity. Nature (London) 256:495-497.

13. Laemmli, U. K. 1970. Cleavage of structural proteins during the assembly of the head of bacteriophage T4. Nature (London) 227:680-685.

14. Land, S., F. Beaton, D. A. McPhee, and I. D. Gust. 1989. Comparison of core antigen (p24) assay and reverse transcriptase activity for detection of human immunodeficiency virus type 1 replication. J. Clin. Microbiol. 27:486-489.

15. Levy, J. A., A. D. Hoffiman, S. M. Kramer, J. A. Lendis, J. M Shimabukuro, and L. S. Oshior. 1984. Isolation of lymphocytopathic retroviruses from San Francisco patients with AIDS. Science 225:840-842.

16. Montelaro, R. C., N. Lohrey, B. Parekh, E. W. Blakeney, and C. J. Issel. 1982. Isolation and comparative biochemical properties of the major internal polypeptides of equine infectious anemia virus. J. Virol. 42:1029-1038.

17. Nakane, P. K., and A. Kawaoi. 1974. Peroxidase-labeled antibody: a new method of conjugation. J. Histochem. Cytochem. 22:1084-1091.

18. Narayan, O., D. E. Griffin, and J. Chase. 1977. Antigenic shift in visna virus in persistently infected sheep. Science 197:376-378.

19. O'Connor, T. P., Jr., S. Tanguay, R. Steinman, R. Smith, M. Barr, J. K. Yamamoto, N. C. Pedersen, P. R. Andersen, and Q. J. Tonelli. 1989. Development and evaluation of immunoassay for detection of antibodies to the feline T-lymphotropic lentivirus (feline immunodeficiency virus). J. Clin. Microbiol. 27:474-479.

20. Parekh, B., C. J. Issel, and R. C. Montelaro. 1980. Equine infectious anemia virus, a putative lentivirus, contains polypep- 
tides analogous to prototype-C oncornaviruses. Virology 107: 520-525.

21. Pedersen, N. C. 1988. Feline infectious diseases, p. 115-123. American Veterinary Publications, Inc., Goleta, Calif.

22. Pedersen, N. C., E. W. Ho, M. L. Brown, and J. K. Yamamoto. 1987. Isolation of a T-lymphotropic virus from domestic cats with an immunodeficiency-like syndrome. Science 235:790-793.

23. Shelton, G. H., R. M. Waltier, S. C. Connor, and C. K. Grant. 1989. Prevalence of feline immunodeficiency virus and feline leukemia virus infections in pet cats. J. Am. Anim. Hosp. Assoc. 25:7-25.

24. Sparger, E. E. 1988. Feline T-lymphotropic lentivirus infection. Feline Med. (Vet. Learning Syst.) 4:9-14.

25. Talbott, R. L., E. E. Sparger, K. M. Lovelace, W. M. Fitch, N. C. Pedersen, P. A. Luciw, and J. H. Elder. 1989. Nucleotide sequence and genomic organization of feline immunodeficiency virus. Proc. Natl. Acad. Sci. USA 86:5743-5747.

26. Towbin, H., T. Staehelin, and J. Gordon. 1979. Electrophoretic transfer of proteins from polyacrylamide gels to nitrocellulose sheets: procedure and some applications. Proc. Natl. Acad. Sci. USA 76:4350-4354.

27. Witt, C. J., T. R. Moench, A. M. Gittelshon, B. D. Bishop, and J. E. Childs. 1989. Epidemiologic observations on feline immunodeficiency virus and Toxoplasma gondii coinfection in cats in Baltimore, MD. J. Am. Vet. Med. Assoc. 194:229-233.

28. Yamamoto, J. K., H. Hansen, E. W. Ho, T. Y. Morishita, T. Okuda, T. R. Sawa, R. M. Nakamura, and N. C. Pedersen. 1989. Epidemiologic and clinical aspects of feline immunodeficiency virus (FIV) infection in cats from the continential United States and Canada and possible mode of transmission. J. Am. Vet. Med. Assoc. 194:213-220.

29. Yamamoto, J. K., E. Sparger, E. W. Ho, P. R. Andersen, T. P. O'Connor, C. P. Mandell, L. Lowenstine, R. Munn, and N. C. Pedersen. 1988. The pathogenesis of experimentally induced feline immunodeficiency virus (FIV) infection in cats. Am. J. Vet. Res. 49:1246-1458. 